\title{
Sensory regulation of open-field activity in mice: Visual stimulation and discontinuous development'
}

D. D. Thiessen

SCRIPPS CLINIC AND RESEARCH FOUNDATION, LA JOLLA, CALIFORNIA

\begin{abstract}
Abstraet
Wabbler-lethal mice tested daily typically show a drop in open-field activity around 15 or 16 days of age. This drop is often preceded by opening of the eyes and can be delayed but not eliminated by running the mice under non-visual conditions. RIII/Crg1, DBA/2J and $\mathrm{C} 57 \mathrm{BL} / 10 \mathrm{~J}$ inbred strains also show a discontinuous development of open-field activity, not necessarily corresponding to eye opening, It is suggested that total sensory influx tied to the maturation of multiple sensory modalities controls this response.
\end{abstract}

\section{Problem}

While studying the behavioral and morphological development of the wabbler-lethal (wl) mouse from day 5 onward (Thiessen, 1964), it was noted that both the mutant wabbler (wlwl) and its heterozygote littermate (wl+) typically showed a sharp drop in open-field activity around 15 or 16 days of age. Often the animals would freeze in the starting corner of the field and not move during the entire 3-min. test. The peculiarity of the response prompted a re-analysis of the data in terms of associated developmental features. The only outstanding correlate was the opening of the eyes, which generally occurred one or two days earlier than the decline in activity. Figure 1 illustrates this gross association. The data suggest that the onset of visual stimulation sensitizes an animal to the environment and as a result disrupts the progressive development of activity. In order to directly test this notion, additional animals were run in the same open field under conditions of red and white light. If the onset of visual stimulation provokes the drop in activity, then animals run under red light, to which they are apparently insensitive (McClearn, 1960) should not show the response.

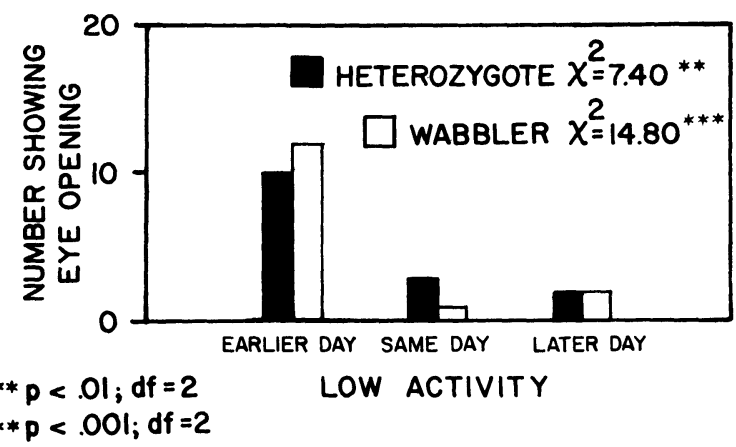

Fig. 1. Number of mice showing eye opening earlier than, on the same day as, or on a later day than a drop in open-field activity.

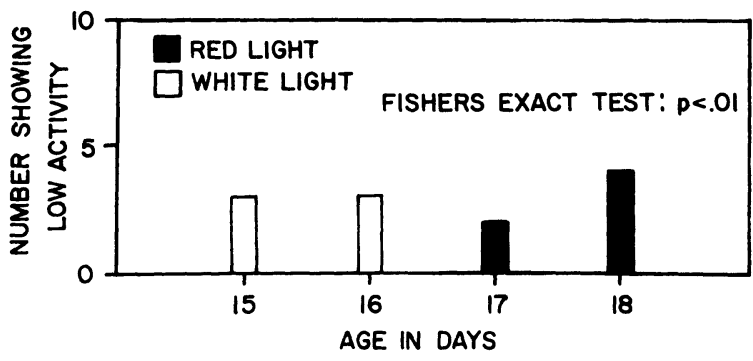

Fig. 2. Number of mice showing a drop in open-field activity under conditions of white and red light.

\section{Method and Resuits}

Twelve heterozygous wabbler-lethal mice were tested for open-field activity as in the previous study. Six were run under standard conditions with a white light incidence of $3.19 \mathrm{ft}$ candles and the other six were run under monochromatic red light (Kodak Wratten A Filter 25 , Series 7 , approximating $650 \mathrm{~m} \mu$ ) with a light incidence of $0.97 \mathrm{ft}$ candles. The day on which animals showed a depression of activity was recorded. As seen in Fig. 2, animals run under white light showed the fall in activity on days 15 and 16, corresponding well with the previous experiment, whereas animals run under red light showed the fall on days 17 and 18. It can be concluded that visual stimulation does play a part in the discontinuous development of activity but is not solely responsible, since activity depression still occurs under non-visual conditions, even though at a later time.

It was suspected that the drop in activity might be specific to the genetic background on which the wl gene

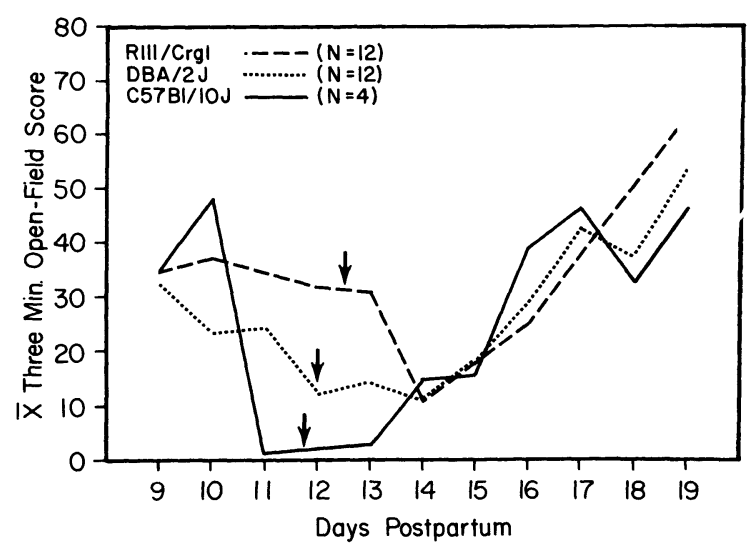

Fig. 3. Development of open-field activity for the RIII/Crg1, DBA/2J and $\mathrm{C} 57 \mathrm{BL} / 10 \mathrm{~J}$ strains of mice. Arrows indicate day of eye opening. 
was segregating. However, additional work with the RIII/ Crg1, DBA/2J and C57BL/10J strains indicates that the discontinuity of behavioral development is a general phenomenon. Figure 3 gives data for these strains over a period of 10 days. Arrows indicate the day of eye opening. Apparently the onset of visual stimulation need not correspond closely with activity depression, since eye opening is seen to precede, correspond with and follow declines in activity.

\section{Diseussion}

While the effects of visual stimulation do seem to play some part in this interesting effect, other sense modalities as well may be involved, Alford \& Ruben (1963) point out, for instance, that the full development of hearing in the mouse occurs around two weeks of age, corresponding well to the origin of the major effect described here. The decline in activity may be a cumulative effect of the total influx of novel stimuli as sense modalities maturate.

\section{Heferences}

ALFORD, B. R., \& RUBEN, R. J. Physiological, behavioral and anatomical correlates of the developing of hearing in the mouse. Ann. Otol. Rhinol. Laryngol., 1963, 72, 1-11.

MCCLEARN, G。E.Strain differences in activity of mice: Influences of illumination. J. comp. physiol. Psychol., 1960, 58, 142-143. THIESSEN, D. D. Behavioral and morphological feaures of the wabbler-lethal mouse. Amer. Psychologist, 1964, 19, 503. (Abstract)

Note

1. This work was supported by Grant MH-06139 from the National Institute of Mental Health.

\section{Comment}

A recent report by Schwartzbaum \& Donovick (1965) demonstrates that cross-talk between intracranial stimulation (ICS) and peripheral shock circuits can affect behavior. They found that Ss receiving low level continuous septal stimulation were impaired on passive avoidance in a food-shock conflict situation only when cross-talk which raised the ICS intensity was permitted. Their study is in some respects similar to studies by Kasper (1963; 1964) and Pellegrino (1965). The latter authors, however, do not feel that the impairments of passive avoidance they observed were the result of electrical cross-talk. Their opinion regarding the occurrence and importance of cross-talk in their experimental situations can be summarized by the following quotation.

Brain stimulation was not discontinued during the mouth shock. However, the oscilloscope was monitored carefully and the brief artifact caused by the mouth shock did not raise the intensity of the brain stimulus. Thus the mouth shock was not associated with high, possibly reinforcing, levels of septal stimulation (Kasper, 1963,p.9).

It seems probable that the apparent difference over the importance of cross-talk between these two sets of authors can be resolved by examining major procedural differences. Schwartzbaum and Donovick used a peripheral shock of $0.8 \mathrm{ma}$ for a duration of $0.5 \mathrm{sec}$. This is in strong contrast to the $0.10-0.15 \mathrm{ma}$ and almost instantaneous shock used by Kasper and by Pellegrino (the shock duration being set by the Ss' reflex times for pulling back from an electrified water spout). The shock situation used by Schwartzbaum and Donovick maximized cross-talk. The situation used by Kasper and by Pellegrino minimized cross-talk by the use of non-shielded short cables, separation of shock and ICS sources and cables, and an ungrounded shock circuit; spread of current between the ICS electrode and the peripheral contact was minimized by the use of a low level of peripheral shock. The lack of an impairment on passive avoidance in Schwartzbaum and Donovick's "no cross-talk" situation as compared to the impairment found by Kasper and by Pellegrino in their "no cross-talk" situation is probably due to the difference in the intensities of punishment.

The problem of electrical cross-talk between ICS and peripheral shock circuits is extremely complex and little understood. Perhaps the use of such noxious stimuli as loud noise or air-blasts would avoid some of the problems of interpretation posed by Schwartzbaum and Donovick's work.

Low level continuous stimulation of the septal region produces behavioral effects in situations where no peripheral shock is involved. One example is an effect on DRL responding (Kaplan, 1965). Another example is an impairment on the reversal of a position habit (Kasper, unpublished data).

Phyllis Kasper Louis Pellegrino McGill University

\section{Referenees}

KAPLAN, J. Temporal discrimination in rats during continuous brain stimulation. Psychon. Sci., 1965, 2, 255-256.

KASPER, PHYLLIS. Attenuation of passive avoidance by continuous septal stimulation. Unpublished Master's thesis, McGill University, 1963.

KASPER, PHYLLIS. Attenuation of passive avoidance by continuous septal stimulation. Psychon. Sci., 1964, 1, 219-220.

PELLEGRINO, L. The effects of amygdaloid stimulation on passive avoidance. Psychon. Sci., 1965, 2, 189-190.

SCHWARTZBAUM, J.S., \& DONOVICK, P.J. An artifact in the use of brain stimulation with shock-motivated behavior. Psychon. Sci., $1965,2,183-184$.

\section{Reply}

The more detailed specification of test conditions employed by Kasper and Pellegrino provides useful and necessary information. Differences in shock intensity and duration, rather than the other variables described, may well have minimized their artifactual electrical cross-talk. Nevertheless, in view of the complexity of the problem and the fact that the behavioral effects of such interactions are poorly understood, it would seem desirable to employ test conditions that eliminate any possible artifact-if only to determine whether brain stimulation at the time of shock is critical for the impairment in passive avoidance.

J. S. Schwartzbaum University of Wisconsin 